\title{
IMPACTOS SOCIOAMBIENTAIS DO PLÁSTICO DESCARTÁVEL: ESTUDO DE CASO NAS REDES DE FAST FOOD EM DOURADOS/MS
}

\author{
SOCIAL AND ENVIRONMENTAL IMPACTS OF DISPOSABLE PLASTIC: \\ CASE STUDY ON FAST FOOD NETWORKS IN DOURADOS/MS
}

\author{
Verônica Maria Bezerra Guimarães ${ }^{1}$ \\ Kimberly Nara Aderno da Silva ${ }^{2}$
}

Recebido em 11/03/2020

Aceito em 10/07/2020

Resumo: O presente trabalho analisou o uso do plástico descartável em redes de fast food no município de Dourados/MS. Da pesquisa, foram percebidos impactos ambientais e sociais causados pelo consumo dos alimentos comercializados. O estudo, através de um levantamento bibliográfico, de dados e de pesquisa qualitativa através de entrevistas semiestruturadas, observou os tipos de impactos causados e como eles afetam o meio socioambiental. Foram identificadas e interpretadas as normativas nacionais que tem por objetivo gerenciar de maneira mais adequada os resíduos sólidos gerados tanto nas zonas urbanas quanto nas zonas rurais, como a Política Nacional de Resíduos Sólidos (PNRS Lei $n^{\circ} 12.305 / 2010$ ) que dispõe sobre a gestão integrada e ao gerenciamento dos resíduos sólidos, bem como, a Política Nacional de Educação Ambiental (Lei no 9795/1999), que é utilizada como instrumento para minimizar os impactos causados pelo plástico de uso único. $\mathrm{O}$ estudo de caso teve o objetivo de analisar a utilização, o gerenciamento e o manejo dos resíduos descartáveis e expor a responsabilidade socioambiental das empresas estudadas. As redes de fast foods foram: Burger King, Subway e Bobố, cujos alimentos são bastante consumidos no Brasil e estão presentes na cidade de Dourados.

Palavras-chaves: Impacto Socioambiental, Plástico Descartável, Redes de Fast Food.

ABSTRACT: The present work analyzed the use of disposable plastic in fast food chains in the city of Dourados/MS. From the research, environmental and social impacts caused by the consumption of commercialized foods were noticed. The study, through a bibliographic survey, data and qualitative research through semi-structured interviews, observed the types of impacts caused and how they affect the socioenvironmental environment. National regulations that aim to manage solid waste generated in both urban and rural areas more appropriately were identified and interpreted, such as the national solid waste policy (pnrs - law no. 12,305 / 2010) that provides for management management and solid waste management. as well as, the national environmental education policy (law no. 9795/1999), which is used as an instrument to minimize the impacts caused by single-use plastic. The case study prepared in the city of Dourados /

\footnotetext{
${ }^{1}$ Docente da Faculdade Direito e Relações Públicas da Universidade Federal da Grande Dourados/UFGD.

${ }^{2}$ Graduada em Gestão Ambiental pela Universidade Federal da Grande Dourados/UFGD.
} 
MS aimed to analyze the use, management and management of disposable waste and expose the socio-environmental responsibility of the companies studied. The Fast Food chains were: burger king, subway and bobôs, whose food is widely consumed in brazil and is present in the city of Dourados.

Keywords: Socioenvironmental Impact, Disposable Plastic, Fast Food Networks.

\section{INTRODUÇÃO}

Atualmente, os resíduos de plástico vêm sendo reconhecidos como grande causadores de impactos socioambientais negativos. Apesar de ser um produto considerado ñversátilò devido a várias utilidades e, consideravelmente, leve, não demandando tanto espaço para armazenamento (em caso de bebidas e alimentos). $\mathrm{O}$ plástico, que é um derivado do petróleo, tem uma vida útil inestimável e sua duração é de poucos minutos nas mãos de quem o consome (no caso de produtos descartáveis), tornando-o um dos grandes vilões da atualidade.

As notícias de degradações ambientais causadas, direta e indiretamente, pelo plástico, poluindo centros urbanos e rurais, mares, rios, matas, além de causar a morte de várias espécies de animais são cada vez mais frequentes. Isso ocorre pelo consumo excessivo de plásticos descartáveis; pela falta de um manejo adequado que sensibilize o consumidor quanto à forma adequada de descartar esse tipo de resíduo e a falta de incentivo para que a população não consuma esse tipo de produto.

Em entrevista para o site das Nações Unidas no Dia Mundial do Meio Ambiente o Secretário-geral das Organizações das Nações Unidas (ONU), António Guterres disse que o mundo deve se unir para ñvencer a poluição por plásticoò e também que ñosso mundo está sendo inundado por resíduos plásticos prejudiciaisò. Afirmou ainda que ñtodos os anos, mais de 8 milhões de toneladas acabam nos oceanosò(ONU, 2018).

Devido à grande presença de plástico nos oceanos, a ingestão desses materiais por várias espécies tornou-se muito recorrente nos últimos tempos, acreditando-se que esses números tendem a aumentar. Pensando nisso, muitas Organizações Não Governamentais (ONG) e instituições tentam fazer com que medidas preventivas sejam tomadas.

Neste sentido, o presente trabalho analisou o uso do plástico descartável em redes de fast food no município de Dourados/MS. Da pesquisa, foram percebidos impactos ambientais e sociais causados pelo consumo dos alimentos comercializados. Foram 
identificadas e interpretadas as normativas nacionais que tem por objetivo gerenciar de maneira mais adequada os resíduos sólidos gerados tanto nas zonas urbanas quanto nas zonas rurais, como a Política Nacional de Resíduos Sólidos (PNRS - Lei n 12.305/2010) que dispõe sobre a gestão integrada e ao gerenciamento dos resíduos sólidos. Bem como, a Política Nacional de Educação Ambiental (Lei n 9795/1999), que é utilizada como instrumento para minimizar os impactos causados pelo plástico de uso único.

O estudo, utiliza como material e método levantamentos bibliográficos, de dados e de pesquisa qualitativa através de entrevistas semiestruturadas, no qual observou os tipos de impactos causados e como eles afetam o meio socioambiental. O estudo de caso elaborado na cidade de Dourados/MS teve o objetivo de analisar a utilização, o gerenciamento e o manejo dos resíduos descartáveis e expor a responsabilidade socioambiental das empresas estudadas. As redes de fast foods foram: Burger King, Subway e Bobâ, cujos alimentos são bastante consumidos no Brasil e estão presentes na cidade de Dourados.

\section{UNIVERSO DO PLÁSTICO}

\subsection{ORIGENS E TIPOS DE MATÉRIAS PRODUZIDOS COM O PLÁSTICO}

O petróleo é um material derivado da decomposição de matéria orgânica. O interesse econômico pelo petróleo teve início no começo do século XIX ao ser utilizado como fonte de energia, substituindo o gás proveniente da destilação do carvão vegetal para a iluminação pública, o chamado "petróleo iluminante". Esta função perdurou apenas até as décadas de 1870/80, quando Thomas Edison conseguiu sistematizar e desenvolver o conhecimento em energia elétrica, suplantando qualquer outra fonte de iluminação. Com isto, o interesse comercial pelo fóssil reduziu drasticamente, voltando apenas no final do século XIX principalmente no século XX, a partir da invenção dos motores a gasolina e a diesel (COSTA, 2007). De acordo com o conceito básico utilizado pela Associação Brasileira da Indústria do Plástico:

Os plásticos são polímeros formados pela união de grandes cadeias moleculares chamadas macromoléculas que por sua vez são formadas por moléculas menores chamadas de monômeros. Os polímeros são produzidos por um processo químico conhecido por polimerização, sendo a reação que une a produção dos materiais plásticos o petróleo e o gás natural e também podem ser obtidos a partir de fontes renováveis como, por exemplo, do etanol (álcool etílico) proveniente da cana-de-açúcar (ABIPLAST, 2014). 
O plástico é um polímero que tem como principal matéria prima o petróleo, porém sua composição pode variar para cada tipo de plástico levando em conta seu grau de flexibilidade, resistência (térmica ou mecânica), durabilidade etc. Ou seja, o plástico é um material que aparenta ter um estado sólido em sua estrutura final, porém, pode se tornar flexível ou moldável quando há alguma ação física.

Dentre esses polímeros estão: Poli(etileno) de alta densidade (PEDA); Poli(etileno) de baixa densidade (PEDB); Poli(propileno) (PP); Polímero EVA (copolímero de etileno e acetato de vinila); Copolímero de acrilontrila butadieno e estireno (ABS); Poli(estireno) (PS); Poli(tereftalato de etileno) (PET); Policarbonato (PC); Poliuretano (PU); Resina Epóxi e Resina Fenólica (PINTO, 2012). Cada um possui características, utilidades, aplicações e destinações diferentes. Considera-se importante ter conhecimento sobre as características e as utilidades de cada produto proveniente do plástico, pois ao final da vida útil de cada um destes produtos é necessário que haja uma destinação adequada para o resíduo em questão.

Devido a sua versatilidade, os materiais plásticos estão presentes em praticamente todos os ambientes em qualquer produto que utilizamos. De acordo com Pinto (2012), a análise feita para descobrir o consumo de plástico nos países europeus aponta que as resinas mais utilizadas foram o PEBD, PP, PVC, PEAD, PET e o PS. Sendo que os maiores setores de usuários são os de embalagem (39\%) e construção civil (20,6\%), seguidos dos setores de transportes, agricultura, setor doméstico e do setor eletrônico. Entretanto, uma questão relevante que pode ser formulada diz respeito a real necessidade dos materiais plásticos em várias proporções (PINTO, 2012).

\subsection{A PRODUÇÃo DO PLÁSTICO}

A indústria termoplástica é a responsável pela produção deste produto tão utilizado. Entre os anos de 1950 e 1970 surgiu, principalmente, nas áreas das formações econômicas e sociais de pequena produção mercantil brasileira, uma vasta e diversificada gama de indústrias termoplásticas. Essa indústria nascente já era produto de um Brasil em processo de urbanização que demandava produtos de maior qualidade e que tendia a não mais produzir para o autoconsumo (TUROSSI, 2017). A partir daí as indústrias termoplásticas foram ganhando cada vez mais espaço e seu capital foi crescendo cada vez

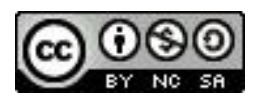


mais. Assim como a funcionalidade de seus produtos que foi ganhando espaço no mercado e conquistando a confiança dos consumidores. Segundo Turossi, 2017:

A partir do surgimento das indústrias montadoras de automóveis que se localizaram no eixo industrial paulista, outras safras de indústrias termoplásticas surgiram. Como é o caso, por exemplo, das indústrias fornecedoras de autopeças de plástico situadas nas cidades do ABC. Também em São Paulo estabeleceram-se indústrias de materiais plásticos para a construção civil, que mais tarde foram superadas concorrencialmente pela Tigre. Além de algumas empresas de embalagens e sacolas rígidas ou flexíveis, todas embaladas pelo crescimento urbano, pela funcionalização do consumo e pelo aumento da acumulação de capital nas esferas da indústria nacional em pleno desenvolvimento.

Em 1950, ano em que se iniciou o desenvolvimento comercial de poliolefinas (polietilenos e poliproplilenos), a produção mundial passou de 1,5 milhão de toneladas; já em 2010, seu crescimento foi para 265 milhões de tonelada, um crescimento de aproximadamente 9\% ao ano (PINTO, 2012).

As indústrias termoplásticas têm um grande valor para a economia, pois, além de toda sua competitividade para a produção, importação e exportação é geradora de emprego para milhares de pessoas e proporciona o crescimento econômico da região na qual se localiza. No Brasil, existem cerca de 11.670 empresas transformadoras, das quais apenas 66 são grandes empresas; 682, médias; 2.722, pequenas e 8.200, microempresas, de acordo com a classificação da RAIS (Relação Anual de Informações Sociais) (ABIPLAST, 2014).

Segundo Schlickmann (2012), a região do ABC Paulista produz produtos para autopeças; o Paraná atua na produção de embalagens rígidas e flexíveis para alimentos e produtos agrícolas; a região Sul e o Nordeste de Santa Catarina na produção dos descartáveis, embalagens flexíveis e tubos e conexões e o Rio Grande do Sul em peças e componentes para equipamentos da agricultura, bem como para veículos pesados. Em todos esses polos, sem exceção, consolidou-se uma gama complexa de produtores de bens e equipamentos, fornecedores de insumos, maquinaria e automação, prestadores de serviços, transportadoras e diversos centros de apoios institucionais ligados à indústria termoplástica.

De acordo com uma reportagem feita pelo site O ECO em março de 2019, sobre um levantamento de dados realizado pela ONG World Wide Fund (WWF), diz que o Brasil é o quarto maior produtor de resíduos plástico do mundo, produzindo cerca de 11 milhões de toneladas por ano, ficando atrás apenas dos EUA, China e Índia. E desse total, foram coletados apenas $91 \%$. Ainda se referindo à publicação da $\mathrm{ONG}$, o site revela que houve

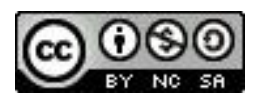


uma compilação de dados disponibilizados para o Banco Mundial, onde foi analisada a produção de plástico em mais de 200 países, afirmando que o Brasil produz, em média, cerca de $1 \mathrm{~kg}$ de resíduo plástico por habitante a cada semana e possui baixa taxa de reciclagem. Revelando que somente 145 mil toneladas do resíduo plástico gerado é reaproveitado, com um índice de 1,28\%, um dos menores da pesquisa que aponta que a média global de reciclagem é de $9 \%$ (OECO, 2019).

\subsection{A Cultura do Consumo}

O consumo de produtos tornou-se um hábito da população em qualquer parte do mundo, passando a ter muita influência sobre a economia de um país, sendo, muitas vezes, incentivada pelo governo, devido à circulação do dinheiro em épocas de crise. Porém, o ato da compra passou muito além da necessidade de se obter um determinado produto, sendo um ñprazer e relaxamentoò para muitos, levando as pessoas a consumirem excessivamente. Segundo Stefani e Lunelli (2014), a sociedade contemporânea é entendida como uma sociedade de consumo, onde os consumidores estão expostos às novas tentações, em um estado de perpétua e pronta insatisfação. De acordo com entendimento desses autores, a sociedade baseia-se em uma lógica pós-moderna, de um capitalismo leve e fluído, onde há uma multiplicidade de escolhas.

Tal situação exigiu que as indústrias produzissem cada vez mais, retirando matéria prima do meio ambiente para a confecção de seus produtos, tornando o modelo atual de produção quase que insustentável. Devido a um modelo de vida mais ñimediatistaò, onde as pessoas visam à praticidade para consumir algum produto, seja um objeto utilizado durante o dia a dia ou alimentos que sejam rápidos e de fácil preparo, as embalagens plásticas acabam sendo as embalagens as mais escolhidas pela população devido a sua leveza e resistência. A utilização do plástico ganhou a confiança, tornando-se popular e muito frequente pelos consumidores. Assim como o uso de sacolas plásticas que vem causando diversos problemas ambientais, que consiste no uso e descarte inadequado. Proibidas em muitos países, elas representam cerca de 4 milhões de quilos de plástico lançados anualmente nos mares (LORENZETT, 2013).

A partir desse padrão de vida adotado pela população, o consumo do plástico descartável passou a ser comum e muito utilizado em: festas, restaurantes (fast food), embalagens de alimento, garrafas de água, entre outros. Contudo, essa praticidade leva a

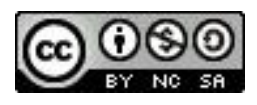


uma destinação final inadequada desses produtos. Sendo possível encontrar tanto nas grandes cidades, quanto nas cidades do interior e do litoral esse tipo de resíduo plástico poluindo as ruas, os corpos hídricos e as matas.

O Congresso Nacional, após muito tempo de debate sobre o tema de disposição inadequada dos resíduos, aprovou da Política Nacional de Resíduos Sólidos (PNRS). A Lei $\mathrm{n}^{\mathrm{o}}$ 12.305/10 marcou o início de uma forte articulação institucional envolvendo os três entes federados: União, Estados e Municípios; o setor produtivo e a sociedade em geral em busca de soluções para os problemas na gestão resíduos sólidos que comprometem a qualidade de vida dos brasileiros (MMA, 2010). De acordo com o relatório realizado pela WWF (2019).

\begin{abstract}
Práticas de consumo acelerado geram uma enorme quantidade de resíduos plásticos, para os quais o mundo não está equipado para lidar. 37\% de todo o lixo plástico não esta sendo tratado de forma eficiente. Quase 310 milhões de toneladas métricas de resíduos plásticos foram geradas em 2016, ou o equivalente a 2.200 garrafas plásticas de água para cada ser humano no planeta, com o nível de resíduos plásticos crescendo a mais de 3\% ao ano desde 2010. No entanto, em 2016, apenas $63 \%$ dos resíduos plásticos chegaram a um ciclo controlado de tratamento de resíduos com baixo risco de criar poluição plástica.
\end{abstract}

Com o crescimento das práticas de consumo, aumentam também as taxas de produção causando aceleração no processo de retirada da matriz no meio natural, o que impede a recuperação do ambiente. Além de haver inadequação na disposição final do resíduo, causa diversos impactos negativos para o meio ambiente. Com a implementação de leis que permitam a instalação de centros de reciclagem, essa saturação da extração de matéria prima pode ser menos extensiva e os materiais já produzidos podem ser reaproveitados, fazendo com que haja redução nos impactos causados pela indisposição desses produtos.

\title{
3. IMPACTOS SOCIOAMBIENTAIS DO PLÁSTICO DESCARTÁVEL
}

\subsection{OS IMPACTOS DO PLÁSTICO}

O plástico está introduzido em diversos setores, nos mais variados tipos de produtos, porém, em muitos casos, sua destinação não é realizada corretamente, principalmente, quando o resíduo plástico é de uso comum como embalagens de alimentos e bebidas, de remédios, de produtos de limpeza, entre outros. A poluição causada por plásticos descartáveis tem interferido em toda a biodiversidade. A introdução do plástico no

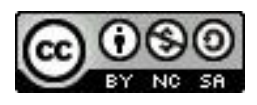


ambiente é proveniente da má gestão dos resíduos, pois, a ingestão dos resíduos sólidos causa impactos ambientais significativos, que podem ser irreversíveis, como a extinção de espécies pelo consumo de micropolímeros através da cadeia alimentar ou pelo ciclo biogeológico, causando assim a intoxicação e a morte de várias espécies devido à ingestão do plástico a partir da sua alimentação, levando a um desequilibro no ecossistema.

Destaca-se ainda que os danos causados aos seres, pelo plástico, não se restringem a ingestão, mas também pela inalação, pois, a combustão desse material lança na atmosfera $\mathrm{CO}$ (Monóxido de Carbono), $\mathrm{CO}_{2}$ (dióxido de Carbono), $\mathrm{CH}$ (hidrocabonetos) e MP (material particulado) (GONÇALVES, 2007). Além de impactos à saúde de seres vivos, os plásticos vêm causando outros problemas ambientais como o aumento no buraco da camada de ozônio, agravando assim os problemas de poluição do solo, das águas e do ar. De acordo com relatório publicado pela WWF (2019):

\begin{abstract}
Estima-se que $87 \%$ do plástico introduzido em uma cadeia de resíduos mal administrada em 2016 tenha sido despejado na natureza e virado poluição plástica. Acredita-se que a maior parte desses resíduos plásticos mal administrados, equivalente a $90 \%$, poluiu a natureza em terra, como o solo e corpos de água potável. Os outros $10 \%$ chegaram, ou espera-se que cheguem, aos oceanos. De todos os resíduos plásticos que chegam aos oceanos, estimase que apenas $1 \%$ fique acumulado na superfície, e o restante acredita-se estar sob a superfície ou no solo oceânico.
\end{abstract}

Os principais impactos que afetam o meio ambiente através do plástico são: enredamento causado por materiais de pesca abandonados; ingestão do plástico (animal e humana); degradação ambiental podendo alterar as condições do solo, da água e dos recifes de corais; impactos na qualidade do ar; descarte inadequado; e os Impactos econômicos que afetam a pesca, o comércio marítimo e o turismo (WWF, 2019).

De acordo com a ONU Meio Ambiente, há necessidade de um alerta para a gestão sustentável do plástico levando-se em consideração todo o seu ciclo de vida. Apontam ainda medidas de proibição ou redução do consumo do plástico descartável, visando combater não só a poluição do solo e dos oceanos, como também combater a poluição do ar (ONU, 2019). A incineração de resíduos plásticos em campo aberto é uma das principais fontes de poluição do ar. Na maioria das vezes, os resíduos sólidos municipais que contêm cerca de $12 \%$ dos plásticos são queimados, liberando gases tóxicos como dioxinas, furanos, mercúrio e bifenilos policlorados na atmosfera. Além disso, a queima de cloreto de vinil poli libera halogênios perigosos e polui o ar, cujo impacto é a mudança climática (VERMA, 2016), causando ou agravando problemas na saúde humana, como

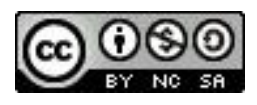


problemas respiratórios, câncer, sensação de sufocamento etc., ameaçando também o bem estar da fauna e flora.

Segundo o site da BBC (British Broadcasting Corporation, um importante site de notícias britânico), mais de $70 \%$ da produção total de plástico é acumulada em ambientes abertos que vão parar em esgotos, em corpos dốgua e nos oceanos (BBC, 2017). Essa fonte traz uma estimativa da quantidade de garrafas pet produzida em todo o mundo em que 480 bilhões de garrafas tenham sido vendidas em todo o mundo até 2016. Tal estatística representa um milhão de garrafas por minuto. Alguns países discutiram maneiras de diminuir o consumo do material. No Reino Unido, que na época em que a pesquisa foi realizada, debateu sobre o oferecimento de água potável e gratuita nas grandes cidades e criação de unidades para devolução de plástico.

Outra pesquisa revelou uma estimativa global de quanto plástico foi produzido, como o material é usado em todas as suas formas e onde ele é descartado. Estes são alguns dos principais dados: 8,3 milhões de toneladas de plástico virgem foram produzidas nos últimos 65 anos; metade deste material foi produzido apenas nos últimos 13 anos; cerca de $30 \%$ da produção histórica continua sendo usada até hoje; do plástico descartado, apenas $9 \%$ foi reciclado; cerca de $12 \%$ foi incinerado, mas $79 \%$ terminaram em aterros sanitários; os itens de menos uso são embalagens, utilizadas por menos de um ano; os produtos plásticos com uso mais longo estão nas áreas de construção civil e maquinaria; tendências atuais apontam para a produção de 12 bilhões de toneladas de lixo plástico até 2050; em 2014, a Europa teve o maior índice de reciclagem de plástico: 30\%, a China veio em seguida com $25 \%$ e os EUA reciclaram apenas $9 \%$ (BBC, 2017).

O plástico pode ser destruído termicamente. Embora existam tecnologias emergentes, como a pirólise, que extrai combustível de resíduos de plástico, até o momento, praticamente, toda a destruição térmica ocorreu por incineração com ou sem recuperação de energia. Os impactos ambientais e à saúde dos incineradores de resíduos dependem fortemente da tecnologia de controle de emissões, bem como do projeto e operação do incinerador (GEYER, 2017). A solução que mais viabiliza a destinação final do plástico é a reciclagem, que transforma o produto original em um produto secundário, aumentando sua vida útil sem que gere muito impacto.

No Brasil, a Política Nacional de Resíduos Sólidos - PNRS criada pela Lei n 12.305 , de 2010 é regulamentado pelo Decreto no 7.404, de 2010, criando como um dos seus

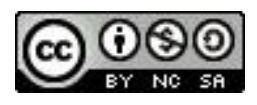


principais instrumentos o Plano Nacional de Resíduos Sólidos. O Decreto n ${ }^{\circ}$ 7.404/2010 instituiu e delegou ao Comitê Interministerial (CI), composto por 12 Ministérios e coordenado pelo Ministério do Meio Ambiente, a responsabilidade de coordenar a elaboração e a implementação do Plano Nacional de Resíduos Sólidos (MMA, 2011).

\subsection{EducaÇÃo Ambiental COMO PREVEnÇão do deSCARTE INADEQUAdo do PLÁSTICO}

Como foi possível observar, o plástico quando descartado inadequadamente pode causar sérios impactos no meio ambiente, afetando a vida de vários seres vivos. E com o atual modo de vida, é praticamente impossível não se utilizar esse material, que em sua grande maioria oferece muita praticidade para quem o utiliza. A inadequação do descarte fere um direito da sociedade, instituído pela Constituição Federal de 1988, no artigo 225, onde dispõe sobre o direito de todos ña meio ambiente ecologicamente equilibrado, bem de uso comum do povo e essencial à sadia qualidade de vidaò, estabelecendo os deveres do poder público e da coletividade para a defesa e a preservação entre as gerações. Nesse mesmo artigo, o inciso VI estabelece o dever de promover a educação ambiental em todos os níveis de ensino e a conscientização pública para a preservação do meio ambiente (BRASIL, 1988).

Uma ferramenta que pode ser utilizada para alcançar esse direito é a Educação Ambiental, que trabalha com a sensibilização e a conscientização das pessoas em diferentes faixas etárias alertando para a importância da preservação, a reciclagem e dos cuidados para com o meio ambiente. De acordo com a Lei n ${ }^{\circ} 9795$ de 27 de abril de 1999, em seu artigo $7^{\circ}$, a Política Nacional de Educação Ambiental envolve em sua esfera de ação, além dos órgãos e entidades integrantes do Sistema Nacional de Meio Ambiente (SISNAMA), instituições educacionais, públicas e privadas dos sistemas de ensino, os órgãos públicos da União, dos Estados, do Distrito Federal e dos Municípios, e ONGô.

Fiorillo (2009) diz que a educação ambiental decorre do princípio da participação na tutela do meio ambiente, como prevista na Constituição Federal, no art. 225, § $1^{\circ}$, VI. Neste sentido, busca-se a efetivação do princípio da participação na salvaguarda do direito ao meio ambiente e a educação ambiental. O autor em comento (2009) afirma que:

educar ambientalmente significa: a) reduzir os custos ambientais, à medida que a população atuará como guardiã do meio ambiente; b) efetivar o princípio da prevenção; c) fixar a ideia de consciência ecológica, que buscará sempre a

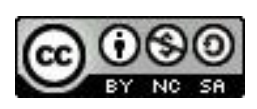


utilização de tecnologias limpas; d) incentivar a realização do princípio da solidariedade, no exato sentido que perceberá que o meio ambiente é único, indivisível, com titulares indetermináveis, devendo ser justa e distributivamente acessível a todos; e)efetivar o princípio da participação, entre outras finalidades.

O principal alvo dos educadores ambientais são as escolas de ensino fundamental e médio, pois, as crianças e adolescentes estão mais suscetíveis a compreender e aceitar as questões ambientais de um modo geral. As ações são passadas nas escolas por meio de palestras e atividades interativas, que tentam gerar um sentimento de conscientização e sensibilização fazendo-as entender a importância da preservação do meio ambiente e os cuidados que se deve tomar para garantir um meio ambiente conservado. Segundo Souza (2013), comportamentos ambientalmente corretos devem ser aprendidos na prática e a escola pode contribuir significativamente para esse processo através da formação de sujeitos críticos e reflexivos capazes de atuar na complexa realidade socioambiental, contemplando sua pluralidade de aspectos.

Através da incorporação da educação ambiental nas escolas pode ser realizados diversos projetos, como a aplicação dos 3R's: reduzir, reutilizar e reciclar sobre o reaproveitamento de materiais recicláveis, aumentando a vida útil destes antes de serem descartados. É comum que a/os educadora/es ambientais trabalhem a importância da separação dos resíduos descartáveis, dando ênfase à coleta seletiva. Quando uma escola ensina os conceitos da educação ambiental para seus/suas alunos/as, tais questões são levadas para seus lares, gerando um ciclo de reflexão e mudanças de hábitos nas suas famílias.

A educação ambiental constitui um processo informativo e formativo dos indivíduos, desenvolvendo habilidades e modificando atitudes em relação ao meio, tornando a comunidade educativa consciente de sua realidade global. Uma finalidade da educação ambiental é despertar a preocupação individual e coletiva para a questão ambiental com uma linguagem de fácil entendimento que contribui para que o indivíduo e a coletividade construam valores sociais, atitudes e competências voltadas para a conservação do meio ambiente. Assim, torna-se necessário mudar o comportamento do homem com relação à natureza, com o objetivo de atender às necessidades ativas e futuras, no sentido de promover um modelo de desenvolvimento sustentável (Soares, 2017). 
A partir destes princípios, o uso da educação ambiental é considerado uma boa ferramenta para a redução do uso do plástico descartável e incentivo à reciclagem deste produto. Tais ações podem levar a um aprendizado pela população, sobre a melhor maneira de descartar um resíduo, reduzindo o impacto ambiental e tentar fazer com que as pessoas repensem seus hábitos de consumo, auxiliando, também, o cumprimento das legislações que se referem à gestão de resíduos e nos serviços prestados pela prefeitura de determinada região.

\subsection{PRINCIPAIS NORMAS E POLÍTICAS PÚBLICAS DE PREVENÇÃo DO PLÁSTICO}

Dos inúmeros resíduos que são descartados de maneira incorreta, os plásticos, principalmente, os de uso único são os mais numerosos. Como sua matéria prima possui uma vasta gama de produtos, é comum que seja o material de maior visibilidade entre os consumidores, colaborando assim com sua enorme quantidade de descarte pós-consumo. O Brasil possui legislações que visam a um adequado gerenciamento dos resíduos sólidos, como a Politica Nacional de Resíduos Sólidos (PNRS) que dispõe em seu artigo $1^{\circ}$ sobre seus princípios, objetivos e instrumentos, bem como sobre as diretrizes relativas à gestão integrada e ao gerenciamento de resíduos sólidos, incluindo os perigosos, às responsabilidades dos geradores e do poder público e aos instrumentos econômicos aplicáveis (L.12305/10). Essa lei possui instrumentos importantes que permite o enfrentamento dos principais problemas ambientais, sociais e econômicos decorrentes do manejo inadequado dos resíduos sólidos.

Outra lei relevante para o tema é a Lei Federal de Saneamento Básico (Lei no 11.445/2007) que aborda o conjunto de serviços de abastecimento público de água potável; coleta, tratamento e disposição final adequada dos esgotos sanitários; a drenagem e manejo das águas pluviais urbanas, além da limpeza urbana e o manejo dos resíduos sólidos. Além de instituir como diretrizes a prestação dos serviços públicos de limpeza urbana e manejo de resíduos sólidos. A partir da Lei n 11.445/07, os resíduos que antes tinham sido descartados inadequadamente, poderão ser destinados a aterros sanitários ou centros de reciclagem, evitando que esse material polua o meio ambiente, e prejudique a saúde da população mais pobre que muitas vezes acabam tendo pouco ou nenhum acesso ao saneamento básico.

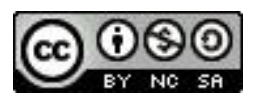


O Instituto Trata Brasil (2019) realizou um estudo sobre a prestação de serviços de água e esgoto nas 81 maiores cidades brasileira, com cerca de 300 mil habitantes, revelando um avanço de 4,5\% em relação ao atendimento de coleta de esgoto e de $14,1 \%$ no tratamento de esgoto entre os anos de 2003 e 2008. Na época em que o estudo foi feito, revelou que 5,9 bilhões de litros de esgoto sem tratamento eram despejados no meio ambiente, contaminando solos, rios, mananciais e praias gerando um impacto não só a natureza, mas também a saúde da população. No estudo, é possível observar que as 81 cidades representam 72 milhões de habitantes, que consomem, em média, 129 litros de água por dia, sendo que $80 \%$ da água consumida se transformam em esgoto e apenas $36 \%$ desse esgoto recebe tratamento adequado. A má gestão dos resíduos sólidos e a falta de saneamento básico tem um grave impacto negativo no meio socioambiental, pois, além de prejudicar todo ecossistema, afeta diretamente a saúde da população, principalmente, das crianças, levando-lhes a sérios problemas de saúde e até mesmo a morte.

Outro importante instrumento é a Resolução do CONAMA (Conselho Nacional do Meio Ambiente) no 275/2001 que auxilia no manejo dos resíduos e na limpeza urbana (uma das exigências da lei ${ }^{\circ}$ 11.445/2017). Esta resolução determina o código de cores, que propicia a identificação das bobonas de coleta de resíduos e nos seus respectivos transportadores, diferenciando os tipos de resíduos por cores, facilitando a separação dos mesmos quando encaminhados para a reciclagem.

A norma da ABNT NBR 10004/2004 classifica os resíduos sólidos, buscando identificar a atividade que gerou determinado resíduo junto a sua característica e composição para uma listagem em que se verifique as substâncias produzidas por esses resíduos e os impactos que podem ser gerados. A segregação dos resíduos na fonte geradora e a identificação da sua origem são partes integrantes dos laudos de classificação, onde a descrição de matérias primas, de insumos e do processo no qual o resíduo foi gerado devem ser explicitados. A identificação dos constituintes a serem avaliados na caracterização do resíduo deve ser estabelecida de acordo com as matériasprimas, os insumos e o processo que lhe deu origem.

Com o aumento dos problemas ocasionados pelo plástico descartável, devido às questões relacionadas à má gestão, algumas prefeituras passaram a tomar medidas de prevenção, que proibisse o uso de alguns descartáveis. Estão sendo implementadas novas

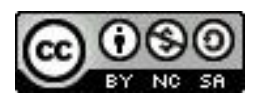


normativas que assegurem a restrição e/ou proibição da circulação deste material, visando ao bem estar do meio ambiente.

O município do Rio de Janeiro foi o primeiro no Brasil a sancionar o Projeto de Lei n 1691 de 2015 que baniu o uso de canudos plásticos em estabelecimentos como bares, restaurantes, lanchonetes e quiosques (RODRIGUES, 2018). Assim como São Paulo que proibiu o uso de canudos plásticos através da lei no 17.110 / 2019 (Assembleia Legislativa, 2019). A lei no 2.625/2019 que também estabelece a proibição dos canudos na cidade de Porto Velho/RO (Prefeitura Municipal, 2019). Várias outras cidades brasileiras estão aderindo a projetos de leis que proíbem o uso de canudos plásticos, sob pena de multa com valores que podem variar para o estabelecimento que não respeitar a esta decisão e para a má disposição do produto.

É muito importante que as cidades tomem medidas para a diminuição do plástico de uso único, tais medidas evitam que uma grande porcentagem de plásticos descartáveis seja despejada inadequadamente nas ruas, nos rios e nos mares. Com a implementação das leis que tenham um grande impacto a favor do meio ambiente, como as do Rio de Janeiro e de São Paulo, essa tendência pode influenciar outras cidades na criação da redução de seus resíduos, levando a uma melhor gestão dos resíduos e do saneamento básico da cidade.

Estas normas se tornam um incentivo para a melhoria ou a implementação de centros de reciclagem, colaborando com a retirada de resíduos de uso único do meio ambiente. Tais medidas tem o intuito de reduzir o número de resíduos plásticos descartados incorretamente e, também, fazer com que a população repense seus hábitos de consumo e entenda a importância da reciclagem e do consumo consciente para a preservação do meio ambiente.

\section{ESTUDO DE CASO DAS REDES DE FAST FOOD EM DOURADOS/MS}

\subsection{CARACTERÍSTICAS DAS REDES DE FAST FOOD}

Nos tópicos anteriores observamos os impactos causados pelo plástico de uso único e como eles afetam o meio ambiente causando poluição em diferentes ecossistemas e na atmosfera, prejudicando a vida dos seres vivos presentes no globo. Aqui, analisaremos os impactos causados pelo uso do plástico descartável disponibilizados por redes de fast food

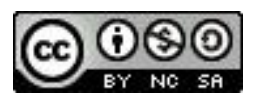


na cidade de Dourados, Mato Grosso do Sul, através de estudo de caso de três redes de fast food: Burger King, Subway e Bobô.

O estudo de caso foi realizado através de pesquisas nos sites oficiais das empresas citadas, analisando sua história de criação; método de trabalho (como perspectiva da quantidade de filiais da empresa); ações de responsabilidade socioambiental e entrevistas semiestruturadas realizada nos estabelecimentos localizados na praça de alimentação do Shopping Avenida Center, localizado na Cidade de Dourados/MS. As entrevistas foram elaboradas com o intuito de levantar dados sobre a gestão e controle dos materiais descartáveis utilizado nestas empresas.

\subsubsection{BURGER KING}

De acordo com o site oficial responsável pela divulgação da empresa, o Burger King (2019) foi fundado no ano de 1954 no Estado da Florida/EUA, por James McLamore e David Edgerton. A empresa possui um cardápio variado de hambúrgueres, porém, o mais conhecido é o Whopper, criado no ano de 1957 e presente até os dias de hoje. O Burger King tornou-se a segunda maior rede de hambúrgueres do mundo, possuindo mais de 15 mil lojas em mais de 100 países ao redor do mundo. O método de trabalho utilizado pela a empresa é o franqueamento. Aproximadamente $90 \%$ dos restaurantes pertencem e são operados por franquias independentes, muitas delas administradas por empresas familiares.

No Brasil, a rede de hambúrgueres teve sua primeira franquia instalada no Shopping Ibirapuera na capital de São Paulo em 2004. Mas apenas em 2011, após o Burger King Corporation ser adquirido pelo grupo $3 \mathrm{G}$ capital, iniciaram-se as operações próprias no país, através de uma joint venture entre Vinci Partners e 3G Capital (BURGER KING, 2019).

Foi a partir de 2011 começaram a crescer no país. Nesta época, possuíam apenas alguns colaboradores em São Paulo, distribuídos entre dezessete pontos de venda. Atualmente, possuem mais de onze mil colaboradores e estão presentes em todos os estados brasileiros, com cerca de seiscentos pontos de venda (BURGER KING, 2019).

A empresa tem como missão: "Ser a mais prazerosa experiência de alimentação." Sua visão é: "Ser a marca de fast food preferida, mais rentável, com pessoas talentosas e forte presença nacional." E seus valores são: ñmeritocracia; foco no cliente; visão de dono; 
alegria; ética e simplicidadeò(BURGER KING, 2019). No site oficial da empresa não foi encontrado nenhum projeto ou ação que visam ao bem estar da população local e nenhum projeto de conservação do meio ambiente de um modo geral.

\subsubsection{SUBWAY}

Segundo o site oficial da rede de fast food, a Subway é uma empresa americana fundada no ano 1965 em Bridgeport, Connecticut/EUA, iniciativa de Fred De Luca, que junto com o seu amigo e sócio, Peter Buck, teve a ideia de abrir uma loja de sanduiches (SUBWAY, 2019).

Em 1974, os dois sócios decidiram expandir os negócios, usando o método de franqueamento como principal sistema. De acordo com o que é relatado em seu site oficial, a companhia é a primeira cadeia de sanduiches com mais de 42.000 estabelecimentos em 110 países, sendo todos eles franqueados. A empresa proprietária registrada da marca comercial Subway em nível internacional é a Doctor's Associates Inc. A empresa procura trabalhar próximo a seus funcionários franqueados e, para isso, contam com uma grande estrutura empresarial de apoio às ações de marketing, publicidade, solicitação de pedidos, além de contar com centros de formação em todo o mundo para garantir uma preparação de ótima qualidade e outras necessidades operativas (SUBWAY, 2019).

De acordo com o site, a Subway tem como visão tornar os restaurantes e as suas operações mais sustentáveis, tentando criar impactos positivos para o meio ambiente, enquanto tentam melhorar a qualidade de vida dos clientes, franqueados, empregados, fornecedores e das comunidades em todo o mundo. Acreditando que as aplicações práticas de negócio boas e sólidas ambientalmente ajudam a elevar a lucratividade dos franqueados, a melhorar a experiência de refeição dos clientes e também proteger o planeta (SUBWAY, 2019).

Segundo as informações disponibilizadas, a empresa tem como comprometimento: a) continuar a desenvolver cardápios com opções saborosas e nutritivas, assim como dar acesso a informações nutricionais e de estilo de vida mais saudável; b) garantir que as refeições cumpram com os mais altos padrões de qualidade e segurança; c) encontrar soluções sustentáveis e de boa relação custo/benefício, que atendam às necessidades de negócios dos franqueados; d) concentrar iniciativas de sustentabilidade em eficiência 
energética, preservação da água e dos recursos, redução de resíduos, compras sustentáveis e gestão da cadeia de suprimentos; e) incentivar os franqueados a contribuir com suas comunidades, a promover a diversidade e escolher opções e práticas de negócios "amigáveis ao meio ambiente" (SUBWAY, 2019). No site diz também que a empresa está fazendo avanços com embalagens sustentáveis de produtos de limpeza e em gestão de resíduos, buscando equipamentos e práticas operacionais mais eficientes (SUBWAY, 2019).

\subsection{3 Вов' $S$}

Segundo informações oficiais da empresa, Robert Falkenburg inaugurou em 1951 sua primeira loja, que na época era conhecida como a Falkenburg Sorvetes Ltda., que vendia exclusivamente sorvete de baunilha, com máquinas e receitas trazidas dos Estados Unidos. Foi por incentivo dos amigos que em 1952 Robert Falkenburg abriu sua primeira loja Bobôs, localizada na Rua Domingos Ferreira, em Copacabana, lançando no Brasil o hot-dog, o hambúrguer, o milkshake e o sundae (BOB's, 2019).

No ano de 1984 a rede de fast food passou a utilizar o sistema de franquias, abrindo duas unidades em Vitória/ES. Nos dias de hoje a empresa possui cerca de 1.100 pontos de venda espalhados pelo Brasil. A visão da empresa é ñser reconhecido como a melhor escolha entre os restaurantes de food service no Brasil, com os produtos mais gostosos e com um serviço diferenciadoò. Sua missão é ñproporcionar uma experiência única aos clientes, com produtos gostosos e saudáveis, em um ambiente moderno e acolhedorò (BOB`s, 2019). No site não foi encontrado nenhum tipo de atividade voltada para a sociedade e nem para o meio ambiente de forma que amenize os impactos negativos causados pela empresa em questões socioambientais.

\subsection{Resultados das EnTrevistas Semiestruturadas nas Redes de Fast} FOOD EM DOURADOS/MS

De acordo com Manzato (2012), o levantamento de dados para pesquisa quantitativa por meio de entrevistas requer cuidado especial. Deve-se considerar que não basta apenas coletar respostas sobre questões de interesse, mas sim saber como analisá-las estatisticamente para validação dos resultados. Segundo o autor os métodos de pesquisa quantitativa, de modo geral, são utilizados quando se quer medir opiniões, reações, sensações, hábitos e atitudes etc. de um universo (público-alvo) através de uma amostra

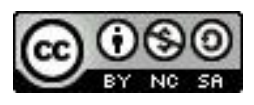


que o represente de forma estatisticamente comprovada. Isto não quer dizer que ela não possa ter indicadores qualitativos (MANZATO, 2012).

O método escolhido para a realização das entrevistas foi o semiestruturado por possuir questões mais abertas e permitir que o entrevistado se sinta mais à vontade em responder as questões a ele proposta. O questionário foi elaborado com o intuito de compreender os métodos de organização dos materiais utilizados nas redes de fast food, dando ênfase nos materiais de uso único. A entrevista foi realizada nas redes Bobô, Burger King e Subway do Shopping Avenida Center localizado na cidade Dourados/MS. As questões que nortearam as entrevistas foram: 1. Qual o cargo do respectivo funcionário? 2. Qual é a quantidade de materiais descartáveis que são utilizados diariamente para que possa atender a demanda? 3. Como é feito o controle do estoque destes materiais? 4. É realizado algum controle dos resíduos que são descartados? 5. Qual a quantidade de materiais descartados? 6. O estabelecimento possui algum sistema para a reciclagem das embalagens? 7. Em caso positivo, como funciona esse sistema de reciclagem? 8. É realizado algum incentivo para que os consumidores evitem a utilização dos plásticos descartáveis? 9. Se sim, quais são os incentivos? 10. O estabelecimento permite que seus consumidores tragam seus próprios itens (copos, canudos, guardanapos etc.) para evitar o uso dos descartáveis? 11. Se sim, é realizada alguma divulgação em relação à permissão do uso pessoal ao invés dos descartáveis?

\subsubsection{RESULTADOS BOBĈ́}

A entrevista foi respondida pelo gerente do estabelecimento, que revelou a quantidade de materiais descartáveis que são utilizados diariamente gira em torno de 1.200, entre copos, canudos, guardanapos. Disse que o controle do estoque dos materiais é feito de acordo com a entrada e saída dos materiais utilizados e marcados no sistema. $\mathrm{O}$ desperdício também é uma forma de controlar os resíduos descartados no restaurante, nesse sentido, ressaltou que não há uma quantidade exata, mas varia entre 30 e 40 por dia. O gerente respondeu também que o estabelecimento possui um sistema de reciclagem, porém apenas para canudos, wrapô (embalagem de lanches) e pacotes para viagem. E disse que o sistema de reciclagem funciona da seguinte maneira: o material é reciclado e utilizado como desmanche para o preparo de outros materiais. Tudo isso por meio das empresas responsáveis, as quais ele não identificou. 
De acordo com a resposta dada na questão oito, o gerente revelou que o incentivo para a diminuição do consumo de produtos de uso único pelos consumidores é ñter a embalagem para viagem feita de papel reciclávelò. Na questão seguinte, ele ressalta o exemplo do papel para viagem. Na questão de número 10, o gerente do estabelecimento deixa explícito que não é permitido que os consumidores levem para o estabelecimento seus próprios matérias como copos, canudos e guardanapos, anulando assim a questão onze.

\subsubsection{RESULTADOS SUBWAY}

O questionário foi respondido pela gerente do estabelecimento, informando que a quantidade de material utilizado é de 2.500, entre canudos, guardanapos e copos de plástico. Informou que os produtos são comprados a cada quinze dias, com controle de entrada e saída no sistema. O controle dos resíduos é lançado como desperdício e não possui um número exato de descarte de materiais.

$\mathrm{Na}$ questão de número seis, a gerente diz que no estabelecimento só é feita a reciclagem de óleo usado na cozinha e não das embalagens, anulando assim a questão de número sete. Revelou que não é realizado nenhum tipo de incentivo para que os consumidores abandonem o hábito de utilizar produtos descartáveis e que não é permitido que os clientes usem seus utensílios ao invés de aceitar os que são oferecidos no restaurante. Apenas os funcionários podem trazer seus próprios copos. As questões 9 e 11 não foram respondidas pela gerente.

\subsubsection{RESULTADOS BURGER KING}

Em relação ao Burger King, o estabelecimento é gerenciado pela mesma pessoa que gerencia a rede da Subway. Ela procura gerenciar os dois restaurantes da mesma maneira, então por isso as respostas para os dois não diferem muito. Assim como na Subway, a quantidade de materiais utilizados são de 2.500 entre canudos plásticos, guardanapos e copos de papel. No sistema é marcado o controle de entrada e saída dos produtos e as compras de reposição são feitas quinzenalmente. Para o controle dos materiais descartados é lançado no sistema como desperdício, porém não possuem números exatos. A gerente diz que não há sistemas para realização da reciclagem dos produtos descartáveis, apenas para o óleo da cozinha. Diz também que não é realizado nenhum incentivo para que os consumidores deixem de usar os descartáveis oferecidos, além de

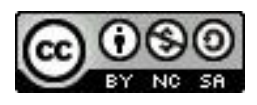


não permitir que os clientes usem os seus próprios copos, canudos etc. Assim como no outro restaurante gerenciado por ela, só os funcionários podem levar seus utensílios. As questões 7, 9,11 não foram respondidas pela gerente.

Como foi observado, no site das empresas estudadas, a única empresa que diz possuir ações que beneficiem a sociedade e busca diminuir os impactos ambientais é a Subway, as ouras duas empresas não foram encontradas nenhuma ação que beneficiem a população e o meio ambiente.

\section{CONSIDERAÇÕES E RESULTADOS FINAIS}

As entrevistas foram aplicadas na praça de alimentação do shopping Avenida Center, com os gerentes dos estabelecimentos escolhidos. Em relação à entrevista realizada no restaurante Bobôs, o gerente não se mostrou disposto a nos atender como pesquisadoras, pedindo para que uma atendente do restaurante intermediasse nosso contato com ele e levasse a folha com o roteiro de perguntas até ele para que o mesmo pudesse responder. Em relação ao Subway e a Burger King, os restaurantes são gerenciados pela mesma pessoa, que procura trabalhar da mesma maneira nos dois estabelecimentos, desta forma as respostas do roteiro ficaram parecidas. A gerente dos dois restaurantes foi bem mais receptiva e atenciosa apesar de estar ocupada com diversos afazeres dos dois restaurantes. De acordo com os sites pesquisados, as empresas revelam que apesar dos treinamentos oferecidos para manter a qualidade dos produtos e o rápido atendimento, as suas franquias têm total liberdade para gerir o restaurante da forma que acharem necessário. O que significa que a filial pode ou não ter programas de reciclagem e coleta seletiva dos materiais de uso único em seus respectivos estabelecimentos. A tabela a baixo ilustra de maneira mais simplificada os resultados citados nas respostas das redes de fast food.

Tabela 1: Resultado das Entrevistas Semiestruturadas

\begin{tabular}{|l|l|l|}
\hline \multicolumn{3}{|c|}{ Tabela de Resultados } \\
\hline Empresas Entrevistadas & Quantidade de Materiais Diários & Resíduos Descartados \\
\hline Bobô & 1.200 & 30 a 40 p/ dia \\
\hline Burger King & 2.500 & Sem quantidade exata \\
\hline Subway & 2.500 & Sem quantidade exata \\
\hline
\end{tabular}

Fonte: autoras.

Na tabela, podemos observar que o número de materiais utilizados entre os restaurantes não é tão distantes uns dos outros. Porém, o resultado da quantidade de 
materiais que são descartados, não revela, adequadamente, o número real de resíduos, levando-se em conta que só o Bob's revelou, mais ou menos, a quantidade de materiais descartados ao dia.

A pesquisa foi realizada em apenas três restaurantes de fast food diferentes em um único lugar (a praça de alimentação de um shopping). Se a pesquisa tivesse uma amplitude maior, os resultados certamente iriam dobrar ou até mesmo triplicar seu valor. Nem todos os restaurantes possuem sistemas de reciclagem destes resíduos, o que causaria a diminuição da vida útil de um aterro sanitário ou aumentaria a quantidade de resíduos alocados indevidamente.

Apesar da responsabilidade social e/ou ambiental que algumas empresas pregam, na maioria das vezes os métodos sustentáveis de gerenciamento não são implementados pelos seus gerentes, como por exemplo, no caso da Subway, onde podemos observar a intenção da filosofia empresarial no site oficial, mas que não pratica seus métodos ñambientalmente amigáveisò. $\mathrm{O}$ que nos leva a pensar, que muitas vezes esse apelo socioambiental, pode apenas ser uma jogada de marketing com interesse em aumentar seus lucros, do que realmente uma preocupação o meio ambiente.

Está cada vez mais claro que o atual modelo de vida da população é insustentável e esse hábito exagerado de consumo, incentivado pelo capitalismo, é prejudicial à saúde de todos os seres vivos. Já que o problema do consumismo não está só na produção retirada da matéria prima de seu ambiente natural ï mas, também, na disposição final que esse produto terá. Todo esse processo tem um grande impacto para o meio ambiente.

Os impactos que os resíduos podem causar são variados como no caso da incineração, gera gases tóxicos que são prejudiciais à saúde causando ou agravando problemas respiratórios, bem como contribuir para as mudanças climáticas; agravar problemas de saneamento básico, podendo gerar doenças e em alguns casos mais graves a morte das pessoas; além da disposição em rios e mares afetando completamente a biodiversidade aquática.

É importante que as legislações vigentes de gerenciamento de resíduos sejam seguidas e que sejam implementados projetos de educação ambiental para que haja sensibilização das pessoas em relação às questões ambientais. Fazendo-as entender sobre a importância da coleta seletiva e da reciclagem, para que a poluição causada por esses 
resíduos seja reduzida ou até proibidas de serem consumidas, como é o caso dos canudos plásticos.

\section{REFERÊNCIAS}

ABIPLAST. Conceitos básicos sobre materiais plásticos. 2014. Disponível em: <http://file.abiplast.org.br/download/links/links\%202014/materiais_plasticos_para_site_ vf_2.pdf>. Acesso em: 07 jul. 2019.

BBC. Cinco gráficos que explicam como a poluição por plástico ameaça a vida na Terra. 2017. Disponível em: <https://www.bbc.com/portuguese/geral-42308171>. Acesso em: 18 out. 2019.

BOBôs. Pioneirismo, Criatividade e Qualidade. Disponível em: <https://www.bobs.com.br/sobre>. Acesso em: 01 nov. 2019.

BURGER KING. Sobre o Burger King. Disponível em: <http://www.burgerking.com.br/sobre-bk>. Acesso em: 01 nov. 2019.

BRASIL. Constituição da República Federativa do Brasil. 1988. Disponível em: <http://www.planalto.gov.br/ccivil_03/Constituicao/Constituicao.htm>. Acesso em: 30 out. 2019.

COSTA, Armando João Dalla, ORTIZ NETO, José Benedito. A Petrobrás e a exploração de petróleo offshore no Brasil: um approach evolucionário. 2007. Disponível em: $<$ http://www.scielo.br/scielo.php?pid=S0034-

71402007000100006\&script=sci_arttext\&tlng=es >. Acesso em: 10 abr. 2019.

FIORILLO, Celso Antonio Pacheco. Curso de Direito Ambiental Brasileiro. São Paulo: Saraiva, 2009.

LORENZETT, Juliana Benitti et al. Sacolas plásticas: uma questão de mudança de hábitos. 2013. Disponível em: <https://periodicos.ufsm.br/index.php/remoa/article/view/7725>. Acesso em: 01 out. 2019.

MANZATO. A Elaboração de Questionários na Pesquisa Quantitativa. 2012. Disponível em:

<http://www.inf.ufsc.br/ vera.carmo/Ensino_2012_1/ELABORACAO_QUESTIONAR IOS_PESQUISA_QUANTITATIVA.pdf>. Acesso em: 02 nov. 2019.

MMA. Plano de Gestão de Resíduos Sólidos: manual de orientação. 2011. Disponível em:

<https://www.mma.gov.br/estruturas/182/_arquivos/manual_de_residuos_solidos3003_ 182.pdf>. Acesso em: 28 out. 2019. 
MMA. Resíduos Sólidos. 2010. Disponível em: <https://www.mma.gov.br/cidadessustentaveis/residuos-solidos>. Acesso em: 07 out. 2019.

OECO. Brasil é o quarto país que mais produz lixo plástico no mundo. 2019. Disponível em: <https://www.oeco.org.br/blogs/salada-verde/brasil-e-o-quarto-pais-que-maisproduz-lixo-plastico-no-mundo/>. Acesso em: 31 ago. 2019.

ONU. Mundo está sendo ốnundadoô por lixo plástico. 2018. Disponível em: $<$ https://nacoesunidas.org/mundo-esta-sendo-inundado-por-lixo-plastico-diz-secretariogeral-da-onu/>. Acesso em: 25 mar. 2019.

ONU. Meio Ambiente alerta para poluição causada pela queima de lixo plástico. 2019. Disponível em: < https://nacoesunidas.org/onu-meio-ambiente-alerta-para-poluicaocausada-pela-queima-de-lixo-plastico/>. Acesso em: 14 out. 2019.

PINTO, José Carlos. Impactos ambientais causados pelos plásticos: uma discussão abrangente sobre os mitos e os dados científicos. Rio de Janeiro: e-papers, 2012.

SCHLICKMANN, P. H. Estudo geográfico das indústrias de plástico de São Ludgero. $2012 . \quad$ Disponível em: <https://repositorio.ufsc.br/xmlui/bitstream/handle/123456789/100413/313367.pdf?sequ ence $=1 \&$ isAllowed $=y>$. Acesso em: 31 ago. 2019.

SOARES, Liliane Gadelha da Costa. Educação ambiental aplicada aos resíduos sólidos na cidade de Olinda/PE: um estudo de caso. 2017. Disponível em: < http://www.unicap.br/revistas/revista_e/artigo5.pdf>. Acesso em: 31 out. 2019.

SOUZA, Girlene Santos et al. Educação Ambiental como ferramenta para o manejo de resíduos sólidos no cotidiano escolar. 2013. Disponível em: <http://revbea.emnuvens.com.br/revbea/article/view/2443/2638>. Acesso em: 30 out. 2019.

STEFANI, Caroline Rossatto. Resíduos sólidos na sociedade consumerista pós-moderna e as políticas públicas municipais: os desafios para o desenvolvimento sustentável. 2014. Disponível em: <https://repositorio.ucs.br/xmlui/bitstream/handle/11338/949/Dissertacao\%20Caroline \%20Rossatto\%20Stefani.pdf? sequence=1\&isAllowed=y>. Acessado em: 20/09/20019.

SUBWAY. História. Disponível em: <http://subwaypt.com/pt/subway/historia.html>. Acesso em: 01 nov. 2019.

SUBWAY. Nosso Compromisso. Disponível em: <https://www.subway.com/ptBR/AboutUs/SocialResponsibility/OurOverallCommitment>. Acessado em: 01 nov. 2019.

INSTITUTO TRATA BRASIL. Por que a universalização do saneamento básico é uma meta tão difícil de ser atingida no Brasil? 2019. Disponível em: 
$<$ http://www.tratabrasil.org.br/por-que-a-universalizacao-do-saneamento-basico-e-umameta-tao-dificil-de-ser-atingida-no-brasil---pensar-brasil>. Acesso em: 31 out. 2019.

TUROSSI, Kelvin Luan et al. Formação do arranjo produtivo do plástico no sul catarinense: histórico e projeções. 2017. Disponível em: $<$ http://revista.fct.unesp.br/index.php/formacao/article/view/4883>. Acesso em: 31 mar. 2019.

VERMA, Rinku et al. Toxic pollutants from plastic waste: a review. 2016. Disponível em: <ttps://www.sciencedirect.com/science/article/pii/S187802961630158X>. Acesso em: 14 out. 2019.

WWF. Solucionar a poluição plástica: transparência e responsabilização. 2019. Disponível em: <https://www.wwf.org.br/?70222/Brasil-e-o-4-pais-do-mundo-quemais-gera-lixo-plastico\#>. Acesso: 04 set. 2019. 